\title{
V.
}

\section{Beiträge zur Kenntniss der Degeneration und Regeneration von quergestreifter Musculatur nach Quetschung.}

\author{
Von Dr. Richard Erbkam, z. Z. in Wien.
}

(Hierzu Taf. II.)

Obgleich man der Frage nach der Regeneration und Patbologie der quergestreiften Musculatur erst in neuerer Zeit näher getreten ist, so hat sich doch über diesen Gegenstand eine so reiche Literatur angesammelt, dass man daraus sowohl die Wichtigkeit der Frage selbst, als auch die Schwierigkeit, sie endgültig zu entscheiden, ermessen kann. So gewiegte Forscher auch, wie: Waldeyer, Zenker, Weber u. A. sich hiermit beschäftigt haben, so wenig haben sie sich einigen können über die Hauptpunkte bei dieser Frage, und alle späteren Forscher haben sich bald auf diese, bald auf jene Seite geschlagen, obne wesentlich Neues herbeizubringen, oder das bisher Gefundene zu widerlegen.

Da in den neueren Arbeiten mehrfach die historische Entwickelung dieser Untersuchungen mit Angabe der Literatur ${ }^{1}$ ) dargestellt ist, so vermeide ich es, hier noch einmal ausführlicher darauf zurückzukommen, begnüge mich vielmehr mit wenigen historischen Angaben, wobei ich die Hauptarbeiten in dieser Frage und ihre Resultate, sowie die Untersuchungsmethoden kurz berühre.

Nachdem zuerst Untersuchungen von Geschwülsten in quergestreifter Musculatur das Interesse für die Veränderungen der Muskelfasern in krankhaften Zuständen geweckt hatten, wurden Beobachtungen über die Veränderungen der Muskelfasern ${ }^{2}$ ) bei der Trichinose gemacht. Bald darauf erschien die Monographie von Zenker ${ }^{3}$ ),

1) S. besonders Lüdeking, Untersuchungen über die Regeneration der quergestreiften Muskelfasern. Dissertation. Strassburg 1876.

2) Fiedler, dieses Arch. 30. 1864 u. Colberg, Deutsche Klinik 1864.

3) Zenker, Ueber Veränderung der willkürlichen Muskeln im Typh. abdom. 1864. 
$\stackrel{8}{8}$

.
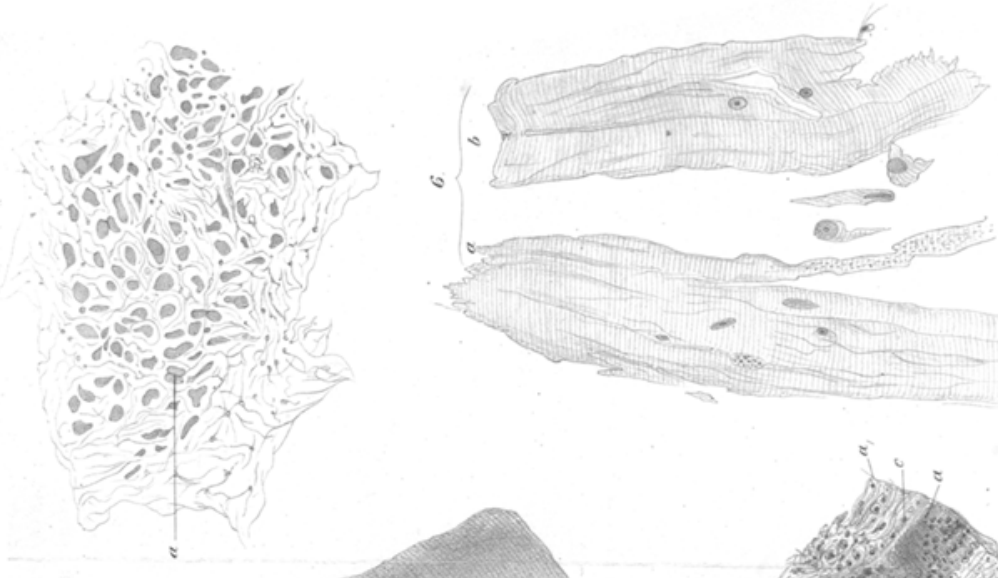

है

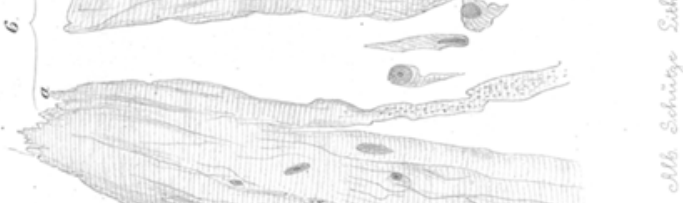

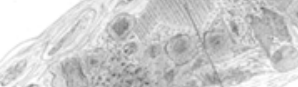

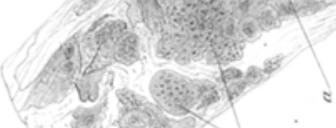

- 82 6

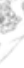

of
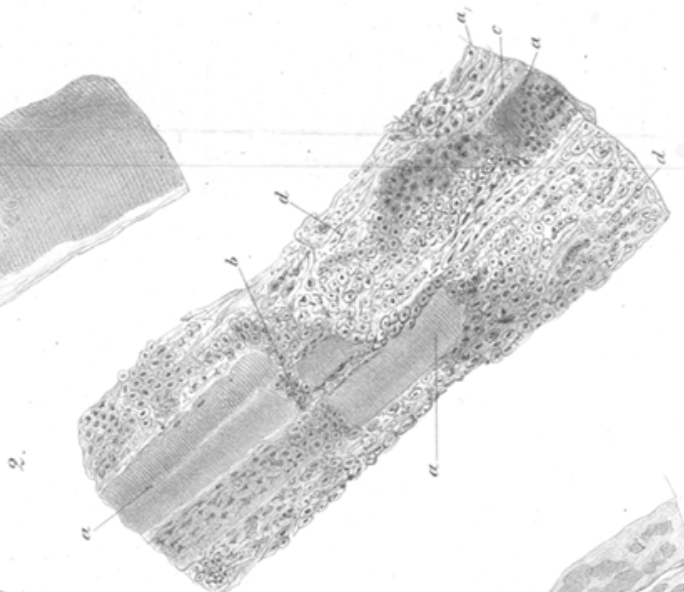

है
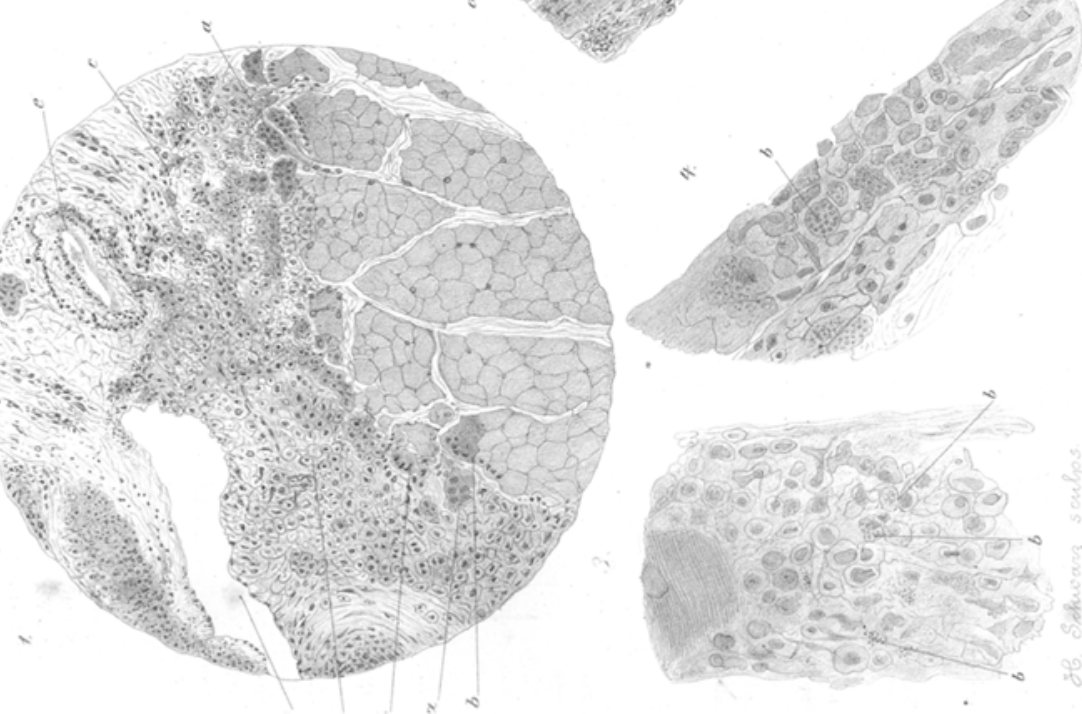
welcher sich als Untersuchungsobject die eigenthümlichen Veränderungen der Musculatur bei Typhus abdominalis gewählt hatte. Als Resultat seiner Forschung stellte er die Ansicht hin, dass die Neubildung von den gewucherten Zellen des Perimysiums ausgehe. Damit trat er auf die Seite jener Forscher, die schon früher aus ihren Studien über die physiologische Regeneration von Muskelfasern an Fröschen zu demselben Resultate gekommen waren. ${ }^{1}$ )

Die folgenden Untersuchungen erstreckten sich theils wieder auf die Typbusmuskeln, theils auf ähnliche Veränderungen der Muskeln bei anderen Infectionskrankheiten ${ }^{2}$ ), theils wurde die Pathologie der Muskeln nach Traumen der verschiedensten Art mit hinein in die Untersuchungen gezogen und der Heilungsvorgang in beiden Fällen mit einander verglichen. Sehr bald stiessen die Resultate der Zenker'schen Untersuchung auf den lebhaftesten Widerspruch, musste doch die Lehre von der Specificität der Gewebe, wenn seine Ansicht die richtige war, bedeutend erschültert werden. Obglejch Waldeyer ${ }^{3}$ ) auf Zenker's Seite tral, deuteten Weber ${ }^{4}$ ), Hoffmann ${ }^{5}$ ), Aufrecht ${ }^{8}$ ) ibre Beobachtung so, dass von den zahlreich gewucherten Muskelkörperchen die Neubildung ausgehe, während Neumann ) und nach ibm Dagott ${ }^{8}$ ) uod in neuester Zeit Lüdeking ${ }^{9}$ ) dieselbe in wieder anderer Weise als einen Wucherungsprozess der alten Muskelfasern auffassten. Gussenbauer ${ }^{10}$ ) nimmt eine vermittelnde Stellung. Er lässt die jungen Muskelfasern theils aus den schollig zerklüfteten und körnig veränderten alten Fasern, deren Kerne gewuchert scin sollen, hervorgehen, indem sie mit den alten Muskelfasern stets im Zusammenhang bleiben, oder getrennt von diesen aus Spindelzellen sich entwickeln

1) s. Deiters, Arch. f. Anat. u. Phys. 1861. v. Wittich, Königsb. medic. Jabrhücher 1862 .

$\left.{ }^{2}\right)$ Pop off, dieses Arch. 61. 1874.

3) Dieses Arch. 34.

4) Weber, dieses Arch. 39 .

5) Hoffmann, dieses Arch. 40.

6) A ufrecht, ebendaselbst 44 .

7) Neumann, Arch. f. Heilkunde 1868 und Arch. f. mikrosk. Anat. 1868.

8) Dagott, Ueber die Regen. von quergestr. Muskeln nach Verletzungen. Dissert. Königsberg 1869.

9) Lü deking, I. c.

10) G., Arch, für klinische Chirurgie 1871. S. 1010 ff. 
nach Art des embryonalen Typus. Zu ähnlichen Resultaten kommt $\mathrm{Kraske}^{1}$ ), der die jungen Fasern allein aus Muskelzellen hervorgehen lässt, die aus den gewucherten Kernen und der veränderten contractilen Substanz entstehen sollen.

Diesen Ansichten steht die bis jetzt von Maslowsky²) allein gemachte Beobachtung gegenüber, dass die weissen Blutkörperchen an der Regeneration der Muskelfasern theilnehmen.

Die Art der Verletzung an den zu untersuchenden Muskeln wurde meist in der Weise vorgenommen, dass man einen Muskel quer zur Längsrichtung seiner Fasern durchschnitt, entweder subcutan oder mit Bildung einer Hautwunde, die dann sorgfältig geschlossen wurde. Oder es wurden auch kleine Stücke des betreffenden Muskels herausgeschnitten und die Heilung des entstandenen Defects untersucht. Kraske wandte ausser den Schnittwunden noch die Aetzung mit concentrirter Carbolsäure an, um, worauf es ihm besonders ankam, so wenig wie möglich Eiterung in die Wunde $\mathrm{zu}$ bekommen, da nach seiner Ansicht die Regenerationsfähigkeit der Muskeln abnimmt mit der Intensität der Eiterung.

Da mithin die Frage über die Regeneration von Muskelfasern nach traumatischen Eingriffen so wenig endgültig entschieden ist, so wurde mir im Winter 1877-1878 durch Hern Prof. Neumann die Aufgabe zu Theil, von Neuem diesen Prozess zu untersuchen, und zwar mit der Modification, das Trauma durch eine Quetschung hervorzurufen. Die Versuche dazu machte ich anfangs an Fröschen in der Weise, dass ich am Oberschenkel subcutan unter einem Muskelbündel einen Faden durchzog und dann über einen Glasstab dasselbe stark zusammenschnürte. Nach einigen Secunden wurde der Faden gelöst und herausgezogen. Die Experimente führten aber zu keinem rechten Resultat, einmal weil die Winterfrösche auf traumatische Eingriffe sehr träge reagiren, und dann zeigte sich auch, dass das Sarkolem erhalten blieb; mithin war die Verletzung eine sehr geringe. Auch ähnliche Versuche, die jch darauf an Kaninchen anstellte, indem ich mit einer Klemmpincette einzelne Muskeln in grösserer Ausdehnung zu quetschen suchte, führten zu keinem Resultat.

1) Habilitationsschrift. Experimentelle Untersuch. über die Regenerat. der quergestreiften Musculatur. Halle 1878.

2) Wiener Wochenschrift 1868. No. 12. 
Da erschien die Dissertation ${ }^{1}$ ) von Heidelberg, auf die Herr Prof. Neumann meine Aufmerksamkeit lenkte und mich aufforderte, die dort angegebene Quetschungsweise der Muskeln - Umschnürung einer Extremität mit einem Gummischlauch - bei meinen Versucben zu benutzen und zugleich die Resultate, zu denen Hejdelberg gelangt war, einer näheren Prüfung zu unterwerfen.

Heidelberg studirt nur die Veränderung, welche die Musculatur der abgeschnürten Extremität durch die Ligatur erleidet, und findet, dass je nach der Dauer der Ligatur, wie vorauszusehen, der Erfolg für die Erhaltung der Extremität ein verschiedener ist. Nach 12-24stundiger Constriction trat feuchter oder trockener Brand ein; eine 7-10stündige Umschnürung wurde von den Thieren meist gut vertragen. Das Bein schwoll nach Lösung des Gummischlauchs stark an und war gelähmt. Nach einigen Tagen verlor sich die Schwellung, und nach 14 Tagen ungefähr war das Bein wieder gebrauchsfähig. Die mikroskopische Untersuchung der Muskeln in verschiedenen Zeiten nach Lösung der Ligatur ergab zunächst einen Schwund, Untergang der Muskelkerne, statt deren oft nur krümliche Reste zurückblieben. In späteren Stadien findet Heidelberg eine starke zellige Infiltration, auch die von Waldeyer beobachteten Zellenschläuche. Noch später bandartige, feine Streifen, die er für neugebildete Muskelfasern hält, ohne auf diesen Punkt genauer einzugehen und der Frage nach dem Ursprung der neuen Muskeln näher zu treten.

Aber gerade die Beantwortung dieser Frage war mir zur Aufgabe gemacht worden. Da nun die oben genannten Veränderungen der Musculatur, ihre Richtigkeit vorausgesetzt, unzweifelhaft von entscheidendem Einfluss auf die spätere Regeneration der Fasern sein werden, so musste ich zunächst die Angaben Heidelberg's prüfen. Bald war mir klar, dass bei Anwendung seines Verfahreus drei wesentlich verschiedene Momente in Betracht kommen müssen. Die Ligatur nebmlich wird bedingen:

1) Eine starke Entzündung in itrer Umgebung, ganz besonders oberhalb der Quetschstelle, wo die Blutcirculation nicht gehemmt ist.

2) Eine Circulationsunterbrechung. Dieselbe wird frei von allen complicirenden Einflüssen am klarsten sich möglichst weit

1) Zur Pathologie der quergestr. Muskeln. Dissertation 1878. 
von der Ligaturstelle selbst documentiren müssen, also z. B. an der Waden- und Plantamusculatur, und

3) wird die Ligatur bedingen eine directe Läsion der contractilen Substanz in den von dem umschnürenden Gummischlauch selbst getroffenen Muskelbündeln.

Man darf daher a priori annehmen, dass der Heilungsvorgang in den Muskeln durch diese drei Factoren wird beeinflusst werden. Ich hatte also nach jedem Versuch an drei verschiedenen Stellen die Muskeln zu untersuchen: 1) Entfernt von der Quetschstelle. Ich wählte dazu theils die Musculi gastrocnemii, theils den Musculus extensor dig. communis und immer die zwar kleinen und zarten, aber für meine Versuche sehr brauchbaren Plantamuskeln, die zu vier Bündeln vereinigt sich leicht von den Sehnen und Fascien der Fusssohle loslösen lassen.

2) Dicht unterhalb der Ligaturstelle und 3) dicht oberhalb derselben. Die Quetschstelle selbst wurde immer zugleich mit 2) und 3 ) in dje Untersuchung gezogen, da sie natürlich nur von geringer Ausdehnung ist.

Zunächst seien noch einige Bernerkungen gestattet über die Wirkung, welche die Quetschung im Allgemeinen bedingt. Der Eingriff ist ein sehr bedeutender, wie auch die weiter unten folgende makroskopische Beschreibung einer verletzten Extremität zeigen wird. Dieser Punkt verdient aber ganz besonders hervorgehoben $\mathrm{zu}$ werden. Denn wäbrend bei allen früheren Untersuchungen absichtlich oder nicht eine Eiterung der Muskelwunde möglichst beschränkt wurde, ist sie hier in bedeutendem Grade vorbanden, verbunden mit einem starken Oedem, das weit über die Ligaturstelle nach oben hinaufgeht.

Hierdurch muss natürlich der Heilungsprozess sich anders gestalten als bei den früheren Versuchen.

Ich gehe nun zunächst zur einfachen Beschreibung meiner Versuche der Reihe nach über und knüpfe daran die kritischen Auseinandersetzungen über die pathologischen Veränderungen der Muskeln und die daraus resultirende Neubildung derselben.

Die Thiere (Kaninchen) wurden sämmtlich in der Weise operirt, dass ein kräftiger Gummischlauch, so stark wie möglich ausgedehnt, zweimal um eine Hinterextremităt dicht oberhalb des Kniegelenks gewurden wurde, dann wurden die Enden eingeschlingt, 
und damit die Schlinge sich nicht lockerte, unterhalb des Knotens ein starker Faden mehrmals um die dort zusammentreffenden Theile des Gummischlauchs zusammengeschnürt. Die dadurch auf die Extremität ausgeübte Constriction ist eine sehr bedeutende. Der Zuund Abfluss des Blutes ist gehemmt, und stets geriethen die Unterschenkelmuskeln in den Zustand der Starre. Die Extremität selbst war gelähmt. Bei den ersten Experimenten dieser Art liess ich die Stelle, wo die Ligatur zu liegen kommen sollte, möglichst von den Haaren befreien, um die Quetschwirkung zu erhöhen. Die dabei aber leicht vorkommenden Hautverletzungen waren später die Ursache einer pyämischen Infection, woran die Thiere zu Grunde gingen. Ich unterliess daher bald das Abscheeren der Haare und fand, dass keine erweisbare Abschwächung der Quetschwirkung sich zeigte.

Zur Technik meiner Präparate bemerke ich Folgendes: Die Untersuchung frischer Muskeln in verdünnter Kochsalzlösung unterliess ich zwar nie, doch zeigte sich bald, dass sie zur Erkennung der feineren histologischen Verhältnisse durchaus nicht genügte, denn die Kerne traten dabei immer nur äusserst schwach hervor. Ich schnitt daher die oben genannten Muskeln aus und härtete sie in Müller'scher Lösung und Alkohol, oder nur in letzterem, und machte dann Quer- und Längsschnitte je nach Bedürfniss. Um die Muskelfasern besonders gut isolirt zu erhalten, zerzupfte ich feine Längsschnitte, nachdem sie gefärbt waren. Hierzu verwandte ich Hämatoxylin in starker Lösung, und besonders auch Bismarckbraun, das die Kerne sehr stark und schnell färbt und sie so ungemein deutlich hervortreten lässt. In Betreff der letztern Färbungsmethode bemerke ich, dass ein geringer Zusatz von einer starken Alaunlösung eine ganz besonders gute Färbung der Kerne zur Folge hat.

Der erste Versuch wurde angestellt, um allein die Wirkung der Ligatur auf die Muskeln der Extremität zu beobachten. Dazu wurde das Thier, bei dem ein Gummischlauch in der vorhin beschriebenen Weise um eine Hinterextremität herumgelegt war, nach 10 Stunden ohne Lösung der Ligatur getödtet. Makroskopisch waren die Muskeln der verletzten Seite im Vergleich zur unverletzten etwas dunkler verfärbt; an der Ligaturstelle konnte man deutlich die Furche, welche der Gummischlauch dort gebildet hatte, erkennen. Die Muskeln waren hier etwas verdünnt und hyperämisch, doch erstreckte sich diese entzündliche Reaction nur etwa $1 \mathrm{Cm}$. über die Quetschstelle nach oben hinaus. Dem entsprechend zeigten hier die Muskeln unter dem Mikroskop theils eine Kernvermebrung, theils efne reichliche 
Ansammlung von Wanderzellen neben den rothen Blutkörperchen in den Gefässen. Daneben waren Muskelfasern zu sehen, deren contractile Substanz in Zerfall begriffen war und jenen eigenthümlicben Glanz zeigte, wie er bei der wachsartigen Degeneration der Typhusmuskeln so bäufig gefunden wird. Unterhalb der Ligatur waren keine Verănderungen, weder in Beziehung auf die Kerne noch auf das Bindegewebe zu erkennen.

\section{Versuch.}

Die Ligatur lag 19 Stunden. Das Thier wurde 10 Standen nach Lösung derselben getödtet. Aeusserlich war das 0edem an der ganzen verletzten Extremität bemerkenswerth, die Ligaturstelle stark hyperämisch.

\section{Mikroskopischer Befund.}

1) In den Plantamuskeln theilweiser Kernschwond. Die Querstreifung theils sehr deutlich, aber oft unregelmässig angeordnet, theils hat sie einem körnigen Aussehen Platz gemacht. Die Muskelfasern sind brüchig, wie viele Eiorisse beweisen. Auch scheint stellenweise das Sarkolem zu fehlen, denn die Fasern sind unregelmässig, sägeförmig begrenzt. Im M. extensor digit. dieselben Veränderungen vielleicht noch ausgesprochener. Stark gefüllte Blutcapillaren, wenig Wanderzellen. An der Ligaturstelle wenig Kerne, die Muskelfasern eigenthümlich gestaltet durch knotenartige Verdickungen in grösserer oder geringerer Entfernung. Die Querstreifung sehr deutlich.

2) Nach der oberen Grenze der Quetschstelle starke Zerklüftung der Fasern, denen dann die Querstreifung verloren geht. Man sieht Theile dieser Fasern sich fortsetzen in solche, die noch nicht so hochgradig verändert sind. Reichliche Blutergüsse und mit Eiterzellen gefüllte Capillaren drängen die Fasern auseinander. Es sind dies offenbar die Stellen, die schon makroskopisch rothgelb bis rothbraun verfärbt erschienen.

\section{Versuch.}

Das Thier wurde 14 Stunden nach Lösung des Gummischlauchs, der 10 Stunden wirkte, getödtet.

Makroskopisches Aussehen.

Oedem der verletzten Extremität bis in ihre äussersten Theile, die Plantamuskeln waren hellroth bis gelblich, während sie normal eine rothbraune Farbe haben. Besonders gut boten sich dem Auge die veränderten Muskeln an der Quetschstelle dar, nachdem sie auspräparirt waren. Vorherrschend war eine starke Hyperämie des Bindegewebes, die Muskeln selbst hellroth mit feinen rothen Streifen. Die Nervenstämme der Kniekehle sehr byperämisch, aber nicht durebgequetscht, wie Heidelberg ') beobachtet hat. Die Hyperămie erstreckte sich, wie Einschnitte in die Muskeln lehrten, anch in die Tiefe. Unterhalb der Ligatur war sie nur oberflächlich. Die Grenze der Constriction nach oben hin war als eine scharfe, zackige Linie sichtbar.

\section{Mikroskopischer Befund.}

1) In den Plantamuskeln scheint die zellige Infiltration des interstitiellen Bindegewebes ehen zu beginnen. Man sieht die runden Wanderzellen ziemlich

1) 1. c. S. 9 . 
gleichmässig zerstreut. Sie markiren sich durch ibre Form und die starkgefärbten Kerne sehr evident von den Muskelkörperchen. Schnittpräparate lassen auf den ersten Blick eine Verminderung der Muskelkerne nicht erkennen, jedoch wird auch diese deutlich durch Zupfpräparate, welcbe zeigen, dass neben normalen Kernen andere sich befinden, die sehr schmal und blass sind, und noch andere, deren Contouren überhaupt nicht mehr deutlich sich abgrenzen lassen. Das Ganze macht den Eindruck, als ob die Kernverminderung eben ibren Anfang genommen hat, wie es bei einer nur vierzehnstïndigen Lebensdauer des Thleres nicht anders zu erwarten ist. Auch die Querstreifung ist oft sehr unregelmässig, oder hat einem körnigen Aussehen Platz gemacht.

2) In den Wadenmuskeln sind ganz ähnliche Befunde. Kernschwund noch deutlicher. Als Zeichen weiterer Degeneration vielfache Einrisse in den Fasern. Auf Querschnitten erschienen die Muskelfelder auffallend gross; was auf eine Intumescenz der einzelnen Fibrillen deutet.

3) An der Quetschstelle unterbalb der Ligatur ist der Untergang der Kerne noch erheblicher. Die noch vorhandenen sind äusserst schmal und klein geworden, gleichsam zusammengeschrumpft. Ein Zerfallen derselben, wie es Heidelberg beschreibt 1), konnte ich weder hier, noch an den anderen Muskeln constatiren. Hervorzuheben wären noch die starkgefüllten Capillaren und die zahlreichen rothen Blutkörperchen, welche die Fasern oft ganz dicht einhüllen. Weiter nach oben treffen wir wieder auf die schollig zerklüfteten Muskelmassen, in denen von der histologischen Structur wenig mehr zu erkennen ist. Ihnen ist der schon oben erwähnte eigenthümliche Glanz eigen. Andere Fasern zeigen knotige Verdickungen und Einschnürungen. Diese Formen sind offenbar dadurch entstanden, dass die contractile Substanz durch die Quetschung in dem Sarkolem zusammengeschoben ist.

Die oberhalb der Ligatur gelegenen Fasern zeigten einen normalen Kernreichthum.

\section{Versuch.}

Die Ligatur lag 10 Stunden, und das Kaninchen wurde 39 Stunden darauf getödtet.

Bemerkenswerth ist hier, dass die Plantamuskeln noch heller gefärbt erschienen als bel dem Versuch 3. Auch die Muskeln am Unterschenkel waren sehr anämisch, durch Eỉnschnitte konnte man aber auch stellenweise Hyperämien constatiren.

Mikroskopische Untersuchung.

An frischen Präparaten fiel das ungemein körnige Ausseben der Muskeln neben der Querstreifung auf. Es waren stark lichtbrechende, feinste Molecüle, die bald schwarz, bald glänzend aussahen; bei Zupfpräparaten schwammen sie in grosser Menge in dem Glycerin umber und liessen eine eigenthümlich vibrirende Bewegung wabrnehmen. Durch ihr optisches Verbalten erweckten sie den Verdacht, als ob es sich um eine Micrococceneinwanderung handle. Doch ergab die Methylvioletprobe ein negatives Resultat. Osmiumsäure färbte sie nicht schwarz, und auch Eisessig vermochte sie nicht vollständig zu lösen. Ich bin daher über ihre Natur

1) J. c. S. 11. 
nicht in's Klare gekommen. An allen Präparaten unterhalb der Ligatur war deutlich zu constatiren, dass die Degeneration der Muskeln einen Schritt weiter gegangen war; nur wenige Fasern zeigten ein normales Aussehen. Die Querstreifung ist entweder sehr unregelmäsig oder wird verdeckt durch die oben beschriebene feinkörnige Trübung. Ausserdem zeigen die Fasern vom Rande her kleinere oder grössere Einrisse, oft zeigt ein und dieselbe Faser in ihrem Verlauf diese verschiedenen Veränderungen, so dass die Präparate dadurch ein sehr eigenthümliches Aussehen gewinnen.

1) In den Plantamuskeln ist neben einer mässig reichlichen Infiltration des Perimysiums ein Untergang der Kerne zu beobachten. Sie erscheinen zusammengeschrumpft, in kleinere Rudimente zerfallen oder blass und verschwommen. Je feinkörniger die Faser, desto weniger Kerne sind in jhr vorhanden.

2) Ein Gleiches ist von der Dnterschenkelmusculatur zu sagen. Die interstitielle Wucherung scheint noch reichlicher zu sein.

3) Unterhalb der Ligaturstelle am Sartorius ist die Querstreifung sehr gut erhalten geblieben, von den Kernen dagegen sieht man nur hin und wieder kümmerliche Reste, zwischen den Fasern vielfach die runden Wanderzellen, wie dies Querschnitte sehr deutlich veranschaulichen. Die einzelnen Muskelfelder berühren sich nicht mehr wie im normalen Zustande, sondern sind wie mit einem Kranze von Wanderzellen eingeschlossen. Ferner stark gefüllte Blutgefässe an den Stellen, die schon äusserlich rötblich erschienen. Weiter nach oben ist der Kernreichthum wieder normal, dagegen sieht man streifenförmig die Infiltration sich fortsetzen, ebenso auch schollig zerklüftete Fasern, die leicht an ihrem eigenthümlichen Glanz zu erkennen sind. In ihnen finden sich fast immer Wanderzellen.

\section{Versuch.}

Ligatur 10 Stunden, Lebensdaner des Thieres 2 Tage.

Ich gebe hier eine ausfübrlicbe Beschreibung der verletzten Extremität, wie sie sich makroskopisch dem Auge darbot. Bei den vorhergehenden und folgenden Versuchen zeigten sich durchaus ähnliche Befunde, so dass ich mich begnüge, dort die wesentlichen Unterschiede hervorzuheben.

Die Extremität liess sich leicht durch das starke Oedem von der gesunden unterscheiden. Ihr Umfang ober- und unterhalb der Quetschstelle war 1,5 Cm. grösser als auf der gesunden Seite. Die Haut sebr infiltrirt und mürbe, so dass sie leicht beim Abziehen einriss. Das subcutane Zellgewebe war in eine sulzige, durchscheinende Masse verwandelt, welche sich bis über die Kreuzbein- und Inguinalgegend der gesunden Seite hinzog. An der Quetschstelle eine deutliche Furche, die als ein rother oder gelblicher Streifen rings um den Schenkel herumlief. Vorn und aussen war dles weniger in die Augen fallend, da hier meist nur Fascien und Sehnen den Oberschenkel bedecken. Beim Durchschneiden der Unterschenkelmuskeln lief eine klare Flüssigkeit über das Messer.

Während die normalen Muskeln eine transparente Beschaffenheit haben, waren sie hier getrübt und stellenweise röthlich gelb. Mit Loupenvergrösserung erkennt man hier feine Streifen parallel den Muskelbündeln; diese erhalten dadurch ein eigenthümliches fleckiges Aussehen. Sehr ausgesprochen waren diese Veränderungen 
an der vorderen Seite des Unterschenkels, erstreckten sich aber nicht durch die ganze Dicke derselben, sondern beschränkten sich auf eine dünne rindenartige Schicht dicht unter der Fascie.

An der Ligaturstelle, d. h. dicht oberhalb des Kniegelenks zeigt allein der M. sartorius am besten die drei verschiedenen Einwirkungen der Quetschung. Denn der Gummischlauch läuft gerade quer ziemlich in der Mitte über den Muskelbauch, während alle anderen Muskeln theils schon sehnig geworden, theils so dünn sind, dass die Veränderungen an ihnen nur undeutlich zu Tage treten. Beim Kaninchen ist der M. sartorius ein dicker, breiter Muskel, der sich nur mit einer ganz kurzen Sehne an die Tibia ansetzt. An seinem obern Ende, da, wo seine Nerven hineintreten, befindet sich stets ein feiner sehniger Streifen, der, den ganzen Muskel der Dicke nach durchsetzend, eine leichte Einziehung verursacht und nicht zu verwechseln ist mit der Schnürfurche der Ligatur. Dieser Muskel ist vorzugsweise bei den Untersuchungen benutzt worden. Er zeigte in diesem Falle oberhalb der Ligatur einen gelben, dann dunkelrothen, schmalen, zackigen Streifen, an der Quetschstelle ein längeres Stück, das mattgelb erschien und unter derselben braunroth verfärbt endigte.

\section{Mikroskopischer Befund.}

1) In den Plantamuskeln sehr ähnliche Veränderungen, wie beim vorigen Versuch. Nur mit Mühe entdeckt man in den Fasern noch hin und wieder einen Kern. Das Perimysium ist weniger reich mit Wanderzellen durcbsetzt.

2) In der Wadenmusculatur fanden sich einzelne Bezirke vollständig kernlos. Das Gewebe ausserordentlich weich und schlaff, so dass Schnittpräparate schwieriger als sonst darzustellen waren. An anderen Stellen wog die zellige Infiltration vor.

3) An der oberen Grenze der Quetschung stiess man wieder auf die Muskelschollen mit ihrem eigenthümlichen Glanz, meist von weissen und rothen Blutkörperchen umgeben und durchsetzt. Auch bei frischen Präparaten fanden sich Fasern, die durch ihre Dndurchsichtigkeit und ihr körniges Ausseben leicht kenntlich waren. Mit Hämatoxylin färbten sich dieselben sehr intensiv blau, fast schwarz, so dass sie um so greller aus den übrigen hellblau tingirten Fasern hervortraten. Eine bemerkenswerthe entzündliche Wucherung der Kerne in den die Quetsehstelle begrenzenden Muskelschichten konnte ich auch in diesem Stadium nicht wahrnehmen. Dicht unter der Ligaturstelle war die Querstreifang sehr gut erhalten geblieben; die Kerne jedoch waren fast sämmtlich untergegangen.

Ich erlaube mir hier die Bemerkung einzuschalten, die für alle Untersuchungen gilt, dass man sehr leicht verleitet werden kann, in Muskelfasern Kerne za constatiren, die in Wirklichkeit nicht vorhanden sind. Denn die Kerne der Capillaren, welche sehr dicht den Fasern anliegen, über oder unter denselben verlaufen, oder die in ihnen befindlicheo weissen Blutkörperchen haben eine grosse Aehnlichkeit mit Muskelkernen, so dass eine gute lsolirung und sehr aufmerksame Beobachtung dazu gehört, sich vor Verwechselungen zu hüten. 
6. Versuch.

Das Thier wurde nach $3 \frac{1}{2}$ Tagen getödtet, nachdem die Ligatur 8 Stunden eingewirkt hatte.

Die mikroskopische Untersuchung ergab Folgendes:

1) Die Plantamuskeln zeigen ein sehr eigenthümliches Bild. Der breite, wellige Sehnenstreifen in der Mitte des Muskels, an den sich $z$ u beiden Seiten in schräger Richtung die Fasern ansetzen, ist stark mit Zellen infiltrírt. Von den Muskelfasern selbst hat wobl keine ihre normale Structur bebaiten; die meisten sind zu Grunde gegangen, und an ihre Stelle ist ein äusserst zellenreiches Gewebe getreten, in dem sich aber noch sehr deutlich die Richtung der früheren Fasern erkennen lässt. Hăufig genug sind auch noch Muskelfibrillen zu sehen. Sie zeigen einen geschlängelten Verlauf, oft durchbrochen durch hellere Stellen, welche nur zahlreicbe Zellen mit ihren runden Kernen erkennen lassen. Bald sind diese Reste der alten Muskeln lăngere Streifen, bald nur kleinere Stücke oder Schollen. Bei stärkerer Vergrösserung beobachtet man Folgendes: Die längeren Muskelfasern haben eine sehr deutliche Querstreifung neben der jene oben (S. 56) beschriebenen feinen Molecüle wahrzunehmen sind. Auch das Sarcolemm scheint untergegangen oder stellenweise zerstört zu sein. Von Muskelkörperchen erblickt man nichts. Auch die kleineren Fragmente haben noch Querstreifung bewahrt, meist hat sie aber einem körnigen Aussehen Platz gemacht. Alle diese Muskelreste liegen in ein dichtes Gewühl von Zellen eingebettet resp. sind von ihnen durchsetzt. Die letzteren besitzen ganz den Charakter von Wanderzellen. Die runde Form herrscht vor, doch trifft man auch ovale and Spindelzellen an, die bei Zupfpräparaten in dem Glycerin in grosser Menge umberschwimmen. Ihr Protoplasma ist oft klein, oft sehr gross und dann feinkörnig.

2) Im M. extens. dig. und den Gastrocnemii dieselben Veränderungen, Die noch erhaltenen Fasern sind vielfach zerklüftet. Hier wie bej den anderen Muskeln gewinnt man den Eindruck, dass sämmtliche musculöse Elemente dem Untergange anheimfallen. Hervorzuheben wären noch die starkgefüllten Capillaren und Blutextravasate.

3) Ligaturstelle. Längsschnitte durch den M. sartorius, die etwas oberhalb der Quetschstelle begannen und etwas unterhalb derselben aufhörten, gewährten bei schwacher Vergrösserung ein sehr gutes Uebersichtsbild der hier stattgehabten Veränderungen. Oberhalb der Ligatur Längs- und Querstreifung sehr ausgeprägt, geschlängelter Verlauf der Muskeln, Kerne vermehrt. Infiltration des interstitiellen Gewebes. Je weiter nach der Ligaturstelle, desto mebr verschwindet das normale Gewebe, bis es ganz in der Zellenwucherung untergeht, aus der nun mehr oder minder grosse Muskelschollen herrortauchen, besonders die schon oben erwähnten, stark tingirten Fragmente. Weiter nach unten nimmt die zellige Infiltration wieder ab.

Beì starker Vergrösserung zeigt die Untersuchung der Ligaturstelle an Zupfpräparaten einen ganz ähnlichen Befund wie bei den Plantamuskeln. Unterhalb fast totaler Kernschwund und grosse Brüchigkeit der Fasern. Oberhalb finden wir die Zeichen der entzündlichen Kernvermehrung, ohne dass an den Muskelfasern selbst eine wesentliche Veränderung zu constatiren wäre. Sie scheinen mir eine Tendenz, 
in Längsfibrillen zu zerfallen, zu besitzen, daher sie an den Enden sich oft pínselartig aushreiten.

\section{Versuch.}

Der Gummischlauch hatte hier $11 \frac{1}{2}$ Stunden lang eingewirkt, und es erfolgte nach $4 \frac{1}{2}$ Tagen der Tod des Thieres.

Aeusserlich zeigte die von der Haut befreite Extremität dasselbe Bild, wie bei den vorigen Versuchen; zu erwähnen wäre noch, dass ein Muskel am Oberschenkel ganz durchgequetscht war.

\section{Mikrosk opische Untersuchung.}

1) Die Plantamuskeln ähnlich verändert, wie im vorigen Versuch. Der Schwund der alten Musculatur ist noch einen Schritt weiter gegangen und der Anfang zur Bildung neuer Fasern gemacht. Von den alten sind nur wenige mehr oder weniger grosse Schollen sichtbar, die von Zellen umlagert resp. durchsetzt sind. Sie zeigen entweder eine sehr grobe Querstreifung, als ob die Faser auseinander gezogen wäre, und ebenso auch die körnige Degeneration in grösserem oder geringerem Grade; oder man beobachtet an ihnen Spalten und Risse der Länge nach, wodurch ein Zerfall in schmale, feine Bänder angedentet wird. An solchen ist auch eine Querstreifung nicht mehr aachzuweisen. In dea Spalten befinden sich oft Zellen (Fig. 6 a und b). Diesen Spaltungsprozess der alten Muskelfasern veranschaulichen sehr gut Querschnitte. Die breiten Felder der alten Fasern erscheinen in zwei oder mehrere kleinere zerlegt, umgeben von einem dichten Gewühl von Zellen, auch die verschiedensten Uebergangsformen von normal grossen, aber kernlosen Feldern bis zo ihrem Zerfall in viele kleinere Theile. Diesen entsprechen dann die feinen, schmalen Bänder, welche in grosser Anzahl inmitten der Zellenwucherung anzutreffen sind. In ihnen befinden sich zablreiche runde Kerne neben einander oder zu Haufen vereinigt (Fig. 1 and 2). Die Zellen selbst, welche vor allen Dingen die Aufmerksamkeit des Beobachters auf sich ziehen, haben die mannichfaltigsten Formen von der gewöhnlichen Wanderzelle bis zu den spindel- und sternförmigen, andere einen sehr grossen Protoplasmahof von einer feinkörnigen, hellen Masse, die durchans der zerfallenden contractilen Substanz ähnlich sieht. Sie haben die Tendenz, sich in axialer Richtung entsprechend dem Verlauf der zu Grunde gehenden Muskeln aneinander zu lagern und dann zu verschmelzen. Die mit a bezeichnete Stelle von Fig. 2 ist in Fig. 3 bei starker Vergrösserung gezeichnet. Man siebt hier bei a eine die Querstreifung sehr deutlich erkennen lassende Muskelschalle mit dea dicht daran stossenden Zellen. An den helleren Stellen bei $b$ ist das Protoplasma exquisit grobkörniger Natur. Aehnliche Zellen bei b in Fig. 4 und $\tilde{5}$.

2) In der Unterschenkelmusculatur war der Befund ganz derselbe. Nur beobachtete ich auch Muskelbezirke, in denen die Degeneration noch nicht so weit vorgeschritten, vielmehr ungefähr in dem Stadium von Versuch 5 sich befand. Solche Stellen traf ich dicht neben den oben beschriebenen an, so dass nur eine leichte Verschiebung des Präparats nothwendig war, um ein ganz anderes Bild vor Augen zu hahen.

3) Quetschstelle. Die Muskeln dicht unter der Ligatur sind ungemein brüchig, fast kernlos, jedoch ibre Querstreifung sehr ausgeprägt. Zwischen den Fibrillen 
zahlreiche rothe und weisse Blutkörperchen. Etwas weiter oben beginnt wieder die zellige Infiltration, die sich bier in derselben Weise darbietet, wie in den entfernt von der Quetschung gelegenen Muskeln; Rudimente von alten Fasern in grosser Menge. Deber der Ligaturstelle ist die entzündliche Kernvermehrung sehr deutlich, und man erkennt aus einer Vergleichung dieser gewucherten Kerne mit den Zellen und Kernen der untergehenden und sich regenerirenden Muskeln unterhalb der Quetschstelle sehr deutlich, dass es sich hier um zwei ganz verschiedene Prozesse handelt.

\section{Versuch.}

Die Ligatur wirkte wieder 10 Stunden. Nach 9 Tagen worde das Thier getôdtet, dessen umschnürte Extremität noch die Lähmung zeigte. Das Oedem war noch ziemlich stark and reichte bis zum Hoden und Kreuzbein. An den Zehen des umschnürten Beines eine Verletzung, wahrscheinlich in Folge der Anästhesie. Das Unterhautzellgewehe sehr verdickt, so dass das Fell schwer abziebbar war. Die Farbe der Plantamuskeln weisslich grau, ebenso die der Unterschenkel. musculatur, und näher der Ligaturstelle bellroth, fleckig. Diese letztere, ganz gelbweiss, setzt sich scharf gegen die obere Grenze der Quetschung ab als eine feine, zackige, dunkelrothe Linie. Nach unten gehen die Veränderungen der Constrictionsstelle diffus in die Musculatur über.

Mikrosk op ischer Befund.

Im Allgemeinen zeigt sich wieder die feinkörnige Beschaffenheit der Muskeln in verschiedenem Grade, manche Fasern erscheinen dadurch ganz undurchsichtig.

1) Die Plantamuskeln gewähren besonders nach der Färbung mit Bismarckbraun ein sehr eigenthümliches Bild. In den feinen, schmalen, mitunter aber auch normal breiten Fasern, die fast durchgängig nur eine Längsstreifung aufweisen, erkennt man eine überaus grosse Zahl von Kernen. Sie unterscheiden sich insofern von normalen Muskelkernen, als sie mehr rund, nicht langgestreckt sind. Durch eine grosse Menge feiner Kernkörperchen erscheinen sie wie granulirt. Auch das Binde- und Sehnengewebe ist sehr kernreich; von Wanderzellen ist dagegen nur äusserst wenig zu erblicken.

2) In der vorderen und hinteren Unterschenkelmusculatur ist das Bild ein anderes. Auf Quer- und Längsschnitten lassen sich Zonen sehr differeoter Fasern zur Anschaung bringen. Meist von der Oberfläche eines Muskels beginnt die starke, zellige Infiltration, in der auch schon bin und wieder die schmalen, jungen Fasern zu Tage treten, dann folgen mehrere Reihen alter, kernloser Fasern und so fort abwechselnd. Dem entsprechend gestalten sich die Querschnitte. Um die grösseren Gefässe erscheint regelmässig die Zellwucherung am intensivsten, weiter ab kommen dann die bekannten polygonalen Felder der alten Fasern zum Vorschein, jedoch ist der Uebergang nicht ein ganz scharfer, sondern man sieht die Zellen (Fig. 1) zwischen die breiten Felder eindringen und sie dicht umgeben; oder sie sind bereits von einer Seite her in die Muskelsubstanz eingedrungen und haben diese in kleine, runde Fragmente zerlegt. Das Ganze macbt den Eindruck, als ob wir es mit einem im Fortschreiten begriffenen Prozess zu thun baben, der in dem Stadium unterbrochen wurde, das sich jetzt uns darbietet. Zupfpräparate lassen jeden Zweifel an dem Zusammenhang der alten Fasern mit den Zellen verstummen. 
Fig. 2 veranschaulicht Muskelfasern, welche deutlich die Querstreifung, aber keine Kerne zeigen und sich in eine Menge von Zellen auflösen, die innerbalb des Sarkolems sich befinden. Diese sind oft sehr gross, fast epithelähnlich, bald rund oder oval, bald eckig mit mehresen Ausläufern und mit einem grobkörnigen Protoplasma, das ganz wie die Ueberreste der alten Fasern aussieht. Diese selbst sind sehr brüchig, haben keine Kerne, und leicht blättern sich die Querscheiben auseinander.

3) Ligaturstelle. Der exquisit weiss aussehende Theil des M. sartorius zeigt vollständigen Kernschwund, aber sebr ausgeprägte Querstreifung. Je näher der oberen Ligaturgrenze, desto mehr füllen sich die Capillaren. Bei schwacher Vergrösserung erscheint daher ein mit Hämatoxylin gefärbter Längsschnitt wie von schmalen, blauen Linien durchzogen, die die mit Wanderzellen erfüllten Capillaren andeuten. Sonst sind die Veränderungen durchaus äbnlich wie beim vorigen Versuch. Die entzündliche Kernwocherung ist sebr bedeutend, die Fasern selbst zeigen zugleich eine Tendenz, in die Primitivibrillen za zerfallen.

\section{Versuch.}

Die Ligatur blieb nur $5 \frac{1}{2}$ Stunden liegen, dagegen wurde das Thier erst nach 41 Tagen getödtet.

Dasselbe batte sich allmäblich ganz von der Operation erholt. Die bedeutende Geschwulst der linken Extremität war schliesslich zurückgegangen, und dieselbe fühlte sich zuletzt sogar etwas dünner an. An der Ligaturstelle konnte man deutlich eine knotige Verdickung durchfühlen. Eine Lähmung bestand nicht mebr. Nach der Tödtung des Thieres und nachdem zum Vergleich von beiden hinteren Extremitäten die Haut entfernt war, fiel sogleich der Unterschied in der Stärke beider Geine anf. Die Musculatur war vorn wie binten viel dünner als auf der gesunden Seite, dagegen traten die Sehnen der Muskeln viel stärker hervor als dort. Ferner waren die lekzteren viel blutärmer als normal; das Unterhautzellgewebe und die Fascien stärker entwickelt, so dass dem Abziehen der Haut ein viel grösserer Widerstand entgegengesetzt worde als rechterseits. Oberbalb der Ligaturstelle waren keine Veränderungen zu seben. Der Knoten, welcher schon äusserlich zu fühlen war, erwies sich als ein in einer Länge von circa $1 \mathrm{Cm}$. durchgequetschtes Muskelstück, das, in eine gelbbraune Masse verwandelt, einen fettigen Detritus erkennen liess, in dem jede bistologische Structur der Muskeln untergegangen war. Im Tib. anticus fand sich ein Alscess, beim Einschnitt in denselhen entleerte sich ein zăher, gelblicher Eiter. Nach Härtung der Musikeln in Müller'scher Lösung und Alkobol zejgte sich schon bei der Anfertigung von Schnitten ein Unterschied in den einzelnen Muskelbäuchen. Ein Theil war trotz der oben genannten Behandlung sehr weich geblieben, die Muskelfasern hingen nur durch ein äusserst feines Bindegewebe zusammen. Bei der mikroskopischen Untersuchung konnte eine Veränderung dieser Theile nicht constatirt werden. Die Fasern batten die normale Breite, Querstreifung und einen gewöbnlichen Kernreichthum.

Andere Stellen besassen ein viel festeres Gefüge, so dass bier sich die Schnitte viel leichter anfertigen liessen, als an den eben erwähnten Stellen. Mikroskopisch fand sich eine reichliche Bindegewebswucherung, die die einzelnen Muskelfasern 
allseitig umschloss. Sehr deutlich veranschaulichen Querschnitte das Verhältniss der Muskelfasern zum Bindegewebe (Fig. 7). Während im normalen Zustande die Muskelpolygone sich ganz dicht berühren, und erst viele derselben gruppirt zu einem grösseren Felde durch einen schmalen Bindegewebsstreifen von dem nächsten geschieden sind, so zeigte sich hier das Perimysium in dem Maasse gewuchert, dass jeder einzelne Faserquerschnitt von dem nächsten durch verschieden breite, helle Streifen getrennt war. Ausserdem war die Kleinheit der Muskelquerschnitte bemerkenswerth, nur hier und da erblickte man eins, das die Grösse eines normalen erreichte.

Wir haben also, wie schon bei den früheren Versuchen zu constatiren war, Muskelbezirke, welche auf das Trauma in verschiedener Weise reagirten. Einige Muskeln waren in ihrer Lebensfähigkeit wenig beeinträchtigt worden, andere hatten aber durch die Circulationsunterbrechung so gelitten, dass sie zu Grunde gehen mussten. Hier verdient jedoch hervorgehoben zu werden, dass die Ligatur schon nach $5 \frac{1}{2}$ Stunden gelöst worden war, dass also der Effect der Circulationsunterbrechung natürlicher Weise nicht so bedeutend sein konnte, wie bei den frïheren Versuchen, daher auch der Unterschied in den Befunden, vornehmlich in den Regenerationsvorgängen. Da mir üherhaupt für die späteren Stadien der Heilung das genügende Material fehlt, so beschränke ich mich darauf, eine einfache Beschreibung eines solchen gegeben zu haben, und werde mich in dem folgenden kritischen Theil meiner Arbeit nur auf die Versuche 1 bis 8 beziehen.

Schliesslich bemerke ich noch, dass die Versuche 3,4 und 8 im Sommer 1879, die übrigen im Sommer 1878 angestellt wurden.

Es fällt mir für den folgenden Theil dieser Arbeit auf Grund meiner Versuche die Aufgabe zu: 1) die Wirkung einer länger dauernden Circulationsunterbrechung auf die Lebensfähigkeit der Muskeln zu prüfen, wie dies Heidelberg a. a. 0 . bereits früher gethan hat, und 2) als das Wichtigste, die Art und Weise, wie die Neubildung der hierbei zu Grunde gehenden Muskeln vor sich geht, zu erörtern.

Was den ersten Punkt betriff, so ergeben meine Versuche lediglich eine Bestätigung der Ergebnisse, zu denen Heidelberg in seiner Arbeit gelangte ${ }^{1}$ ). $\mathrm{Ob}$ die von ihm angegebenen 10 Stunden die äusserste Grenze bilden für die Erhaltung des umschnürten

1) 1. ... S. 15 . 
Beines, habe ich nicht weiter geprüft, dürfte auch wohl schwer zu entscheiden sein, da neben der Dauer der Ligatur doch auch das Alter, die Kraft und Art des Thieres in Betracht kommt. Auch kann man die Intensität der Quetscbung nicht so genau controliren, dass man mit Bestimmtheit weiss, stets denselben Grad angewendet za haben. Für die Richtigkeit seines wichtigsten Befundes Schwund der Kerne unterhalb der Ligatur als directe Folge der Ernährungsstörung in den Muskeln - können meine Untersuchungen eintreten. Sie überzeugen mich aber auch ferner davon, dass dieser Untergang alle Kerne betrifft, zwar nicht alle auf einmal, aber nach und nach, wenigstens bei den länger dauernden Quetschungen von 8 bis 10 Stunden. Während in einzelnen Muskeltheilen die Kerne schon gänzlich verschwunden sind, so dass kaum mehr einer zu entdecken ist, trifft man sie in anderen noch genug an, aber auch sie gehen in späteren Stadien unter, denn nie habe jch in unzweifelhaft alten Muskelfasern Kerne auch nur in annähernd normaler Zahl gefunden, was doch erforderlich wäre, wenn einige zurückgeblieben und von Neuem wuchern könnten (vgl. Versuche 5, 7 und 8). Hätten die aus dem allgemeinen Untergang sich rettenden Kerne die Fähigkeit, sich zu vermehren, so würden sie mit dieser Eigenschaft schon früher nach zwei, drei Tagen, hervortreten, denn nach dieser Zeit beginnt ja schon die Bildung junger Fasern, wie Versuch 6 zeigt. Statt dessen sehen wir aber in Versuch 8 nach 9 Tagen vollständig indifferent sich verhaltende alte Fasern, deren Kerne und contractile Substanz alle Zeichen der Degeneration an sich tragen.

Ob der Modus des Untergangs - das Zerfallen der Kerne zu krümlichen Resten - der einzige ist, scheint mir aus meinen Versuchen nicht so unbedingt hervorzugehen. Denn erst bei den in diesem Sommer angestellten Experimenten gelang es mir, äbnliche Beobachtungen zu machen, wie sie Heidelberg a. a. 0 . S. 11 beschreibt und abbildet, während eine grosse Anzahl von Versuchen jm Sommer 1878 in dieser Beziehung ein negatives Resultat hatten. Neben dem Zerfallen der Kerne bemerkte ich bei einigen auch ein Blasserwerden, sie färblen sich fast gar nicht oder nur verschwommen, was sich aus einem allmählichen Aufiösungsprozess erklären liesse.

Was den zweiten Punkt anlangt, so muss ich gleich von vorn 
herein bemerken, dass meine Beobachtungen mich zu der Annahme eines Regenerationsvorganges zwingen, der in der Neuzeit von den meisten Forschern verworfen ist, und der mit der jetzt herrschenden Theorie von der Specificität dergạewebe im Widerspruch steht, nehmlich dass auch die Wanderzellen sich an der Neubilduug der Muskelfasern betheiligen. Obgleich ich mir wohl bewusst bin, dass man nach dieser Behauptung meiner Arbeit mit einigem Misstrauen begegnen wird, so wage ich doch, die Hoffnung auszusprechen, dass meine Versuche und die nachfolgende Darstellung und Vertheidigung meiner Ansicht soviel Interesse den Forschern, die sich mit der vorliegenden Frage beschäftigt haben, abgewinnen werden, dass sie vielleicht von Neuem ihre Aufmerksamkeit auf die Regeneration der quergestreiften Musculatur richten werden. Sollte sich Verfasser in dieser Erwartung nicht täuschen, so würde er sich reichlich für die auf diese Arbeit verwandte Mühe belohnt sehen.

Da, wie ich bereits erörtert, meine Versuche mich zu der Annahme führten, dass eine länger dauernde Circulationsunterbrechung einen Untergang der Muskelkerne zur Folge hat, und dass damit Hand in Hand geht eine Degeneration der contractilen Substanz, und trotzdem eine Neubildung stattindet, so war mir zunächst klar, dass letztere entweder nur von den aus dem Untergange geretteten Kernen ausgehen könne, oder dass, wenn alle Kerne untergehen und nicht wuchern können, von aussen her ein neues Element Leben in die todte contractile Substanz bringen müsse. Damil aber hätte die Theorie der Specificität der Gewebe ihre Allgemeingültigkeil eingebüsst, und die ältere Ansicht von der. Umwandlung der Gewebe wäre wieder zur Geltung gekommen.

Da nun aber nach meinen Präparaten der letatere Fall wirklich eingetreten ist, so bleibt mir nichts anderes übrig, als den Zellen, welche schon in den ersten Stadien der Versuche so sehr die Aufmerksamkeit des Beobachters in Anspruch nebmen, die Aufgabe zu vindiciren, den untergehenden Muskeln neue Lebensfähigkeit zu verleihen.

Und zu dieser Annahme berechtigt mich, ich möchte fast sagen, jedes meiner Präparate. Für jeden unbefangenen Beobachter muss es doch äusserst auffallend sein, dass nach einer gewissen Zeit, wie die Versuche 6 und 7 beweisen, kaum ein Muskel mehr vollständig 
erhalten ist. Die Infiltration der Gewebe mit Zellen ist an einigen Stellen so stark, dass man auf den ersten Blick zweifelt, ob man es auch mit Muskelgewebe zu thun hat. Die noch vorhandenen Muskeln sieht man von Zellen voliständig eingeschlossen und durchseizt. Zieht man hiermit in Betracht, dass die früheren Stadien (Versuch 2 bis 5) genau verfolgen lassen, wie die zellige Infiltration allmählich, je länger das Thier nach Lösung des Gummischlauchs am Leben blieb, immer stärker wurde, und wie damit zugleich der Kernreichthum der Muskeln abnahm, so wird man dieser Infiltration einen wesentlichen Einfluss auf den Heilungsprozess zuschreiben müssen.

Welcher Art sind nun aber die Zellen? Quer- und Längsschnitte bei schwacher Vergrösserung (Fig. 1) lassen unschwer erkennen, dass man es hier mit Wanderzellen zu thun hat. Erstere zeigen, wie sie im Umkreis der Gefässe am zahlreichsten auftreten, und wie sie den Verzweigungen der Gefässe folgen. An Längsschnitten, an denen noch fast gar keine Infiltration zu erkennen ist, seben wir die Gefässe, strotzend mit Wanderzellen gefüllt, sich zwischen den Muskeln verästeln und nur eben das dicht anliegende Bindegewebe mit Zellen durchsetzt. In Zupfpräparaten schwimmen diese Zellen in grosser Menge umher und lassen deutlich alle Eigenschaften der weissen Blutkörperchen - kleine, runde, stark gefärble, excentrische Kerne mit hellem Protoplasmahof - erkennen. Freilich sieht man auch andere Formen, auf die ich unten zurïckkomme.

Dass wir es hier keineswegs mit einem vereinzelten, sonst noch wenig beobachteten Vorgang zu thun baben, wird Jeder zugeben, der mit den classischen Versuchen Cohnheim's ${ }^{1}$ ) an der Froschzunge bekannt ist.

Statt der letzteren habe ich hier nur die umschnürte Extremität eines Kaninchens. Ich darf daher wohl die Folgerungen, die Cohnheim aus seinen Experimenten zog, auf die meinigen übertragen. Darnach ist die Infiltration des Muskelgewebes mit Wanderzellen ans einer Alteration (Lockerung) der Gefässwände zu erklären, die durch die Circulationshemmung herbeigeführt wurde. Meine Versuche ergaben aber auch, dass nach Lösung der Ligatur

1) Ueber die embolischen Prozesse. S. 33 ff. 
die Blutcirculation nicht in allen Theilen $\mathrm{zu}$ derselben Zeit gleichmässig wiederhergestellt wird, sondern dass einzelne Muskelpartien früher, andere später von dem Blutstrom wieder durchflossen werden, so dass die aus der Ernährungsstörung resultirenden Veränderungen in dem einen Muskel erst beginnen, während sie in einem anderen schon zu einer Regeneration geführt haben.

Es fragt sich nun aber weiter: Wie verhält sich die Muskelfaser selbst zu diesem massenhaften Austreten der Wanderzellen? Wenn man die Wirkung, die die Umschnürung der Extremität auf die histologisehe Structur der Muskeln sogleich in den ersten Stadien der Experimente äussert, in Betracht zieht, so dürfte es nicht weiter auffallend sein, wenn wir erfahren, dass die Zellen in die Muskeln selbst eindringen und sie gänzlich vernichten oder sonst wie verändern. Das Trübewerden der Fasern, Aufblättern derselben, oder der körnige Zerfall, der Schwund der Kerne, Alles beweist, dass die Muskelfasern in ihrer Resistenzfähigkeit ausserordentlich gelitten haben, sich in einem fortschreitenden Degenerations- oder Macerationsprozess befinden. Sollten die Wanderzellen, welche durch die dicken Gefässwände hindurchgehen können, nicht auch das feine Sarkolem, das zudem noch öfters eingerissen ist, zu überwinden vermögen? Ausserdem kornmt noch der erhöhte Druck in Betracht, der bei dem starken Oedem, das stets gefunden wurde und sehr lange anhält, in den Muskeln vorhanden sein und die in dem Gewebe befindliche Flüssigkeit, d. h. das mit Wanderzellen reich versehene Blutserum in die Muskelschläuche pressen muss.

Dem entsprechen auch meine Beobachtungen. Sie beweisen mir speciell, dass der Zerstörungsprozess der Muskeln ein successiver ist. Während in dem einen nach vier Tagen von unveränderten Fasern nichts mehr zu sehen ist, sind in einem anderen dieselben noch gut erkennbar, aber mit deutlichen Zeichen der Degeneration: Kernschwund, Brüchigkeit, körnige Beschaffenheit der contractilen Substanz; die zellige Infiltration beginnt eben.

Die so entstehenden Zellenschläuche sind schon früher beobachtet worden, zuerst von Waldeyer bei den Typhusmuskeln und dann auch bei der Heilung von Muskelwunden. Er giebt ihnen den Namen Muskelzellscbläuche, da nach seiner Auffassung sie durch Wucherung der Muskelkörperchen entstehen. Ein sehr bäufiges Vorkommen derselben scheint er nicht beobachtet zu baben, 
sonst würde er ihnen nicht eine nur transitorische Bedeutung beilegen können '). Er neigt zu der Ansicht, dass sie durch Resorption verschwinden. Auch seine weiteren Beobachtungen über den Untergang des Sarkolems und über das Auftreten von Muskelzellschläuchen in Fasern, deren Inhalt zerklüftet und deren Spaltstücke zwischen den Muskelzellen im Sarkolemschlauch zerstreut liegen ${ }^{2}$ ), kann ich nicht acceptiren. Liegt nicht die Auffassung sehr nahe, dass in den eingerissenen oder zerstörten Sarkolemschlauch von aussen Elemente eindringen können? Und was sollten diese Elemente wohl Anderes sein als rothe oder weisse Blutkörperchen, da doch durch die Schnittwunden, die Waldeyer anlegt, eine Menge Capillaren und auch grössere Blutgefässe geöffnet werden, und durch die darauf folgende Entzündung eine so grosse Menge von Eiterzellen producirt wird, dass jede Muskelfaser von denselben umlagert resp. durchsetzt werden muss. Ausserdem dürfte die Annahme einer Kernwucherung in Fasern, deren histologische Structur vollständig verloren gegangen ist, nicht recht stimmen mit unseren sonstigen Vorstellungen über Kern- und Zellenvermehrung in den Geweben. Einer derartig zerstörten Faser geht die vitale Eigenschaft der Kernwucherung ab. Ich kann daher den von Waldeyer zuerst gefundenen Gebilden entsprechend meiner Auffassung nur den Namen: Wanderzellschläuche geben.

Ausführlich beschreibt auch Gussenbauer l. c. S. 1031 u. ff. die Wanderzellschläuche an Quer- und Längsschnitten. Er schildert sie folgendermaassen: „Neben völlig unveränderten Faserquerschnitten, an denen die Cohnheim'schen Felder noch deutlich wabrzunehmen sind, finden sich auch solche vor, an denen dies nicht mebr der Fall ist. Diese haben dann entweder eine körnige Beschaffenheit oder ein nahezu homogenes Aussehen angenommen mit dem eigenthümlichen, matten Glanze. An anderen sieht man die contractile Substanz allseitig von farblosen Zellen umlagert, und dann stellen die Faserquerschnitte unregelmässige Figuren mit zackigen Rändern dar. Auch solche Querschnitte kommen zur Anschauung, an welchen die contractile Substanz in mehrere kleinere, rundliche oder eckige Stücke zerspalten ist, und wo in den Spaltrăumen dieselben farblosen Zellen sich vorfinden. An allen diesen

1) Waldeyer. Dieses Arch 34. S. 506.

2) J. c. 482 . 
Formen ist aber der scharfe Sarkolemcontour nicht mehr vorhanden. Am auffälligsten ist dies an solchen, wo von der contractilen Substanz noch eine Mantelzone erhalten ist." Ich brauche zu dieser Beschreibung nichts weiter hinzuzufügen und verweise nur noch zum bessern Verständniss des hier geschilderten Vorgangs auf eine Vergleichung der Gussenbauer'schen Zeichnung I und II, ansgeführt bei starker Vergrösserung, mit der meinigen (Fig. 1) bei schwacher Vergrösserung. Ich glaube, der vorurtheilsfreie Beobachter wird erkennen, dass hier dieselben Prozesse dargestellt sind, und aus meiner Zeichnung dürte er den Eindruck gewinnen, dass es sich hier um einen allmählich fortschreitenden Prozess handelt.

Im Verlauf seiner Arbeit erklärt Gussenbauer diese Zellen der Mehrzahl nach für ausgewanderte Blutzellen. So weit stimmen wir in unseren Beobachtungen überein. Gussenbauer spricht aber noch von anderen Zellen, deren Kerne sebr ähnlich den Muskelkernen und aus den gewucherten Kernen einer „erhaltenen Mantelzone" entstanden seien. Darin kann ich ihm aus den schon oben erwähnten Gründen nicht beistimmen; meine Präparate bieten dafür gar keine Anbaltspunkte.

Forschen wir aber weiter, welche Bedeutung Gussenbauer den Wanderzellschläuchen bei dem Regenerationsvorgang zuerkennt, so vermissen wir darüber jede Angabe.

Auch die neueste Arbeit über die Regeneration der quergestreiften Musculatur von Kraske beschäftigt sich eingehend mit den Muskelzellschläuchen. Er stellt zunächst den Satz auf ${ }^{1}$ ), dass die Regeneration der Muskeln umgekehrt proportional zunimmt mit der Infiltration des Gewebes mit Wanderzellen. Dieser Satz dürfte nach meinen Versuchen eine allgemeine Giltigkeit nicht haben. Dass nach einer Aetzung mit Carbolsäure, wo die Eiterung sehr minimal und die Kernwucherung der Muskeln sehr gross ist, die Neubildung der Fasern sebr schnell vor sich geht, mag schon sein, aber das gestattet nicht den Rückschluss, dass bei einer Muskeleiterung wie bei meinen Versuchen die Regeneration sehr schwach oder gar nicht zu Stande kommt.

Kraske giebt ferner zu, dass er oft Wanderzellschläuche gesehen habe, meint aber, es sei gar nicht möglich, diese mit den

1) I. c. S. 28 . 
eigenthümlichen Muskelzellschläuchen zu verwechseln ${ }^{1}$ ), da diese durch ibre Kerne sich ganz besonders vor jenen auszeichneten. Aus meinen Präparaten habe ich diese Ueberzeugung nicht gewinnen können. Muskelzellschläucbe im Sinne Waldeyer's, die aus den mit Protoplasma versehenen gewucherten Kernen entstanden sind, babe ich überhaupt nicht beobachtet. Die Muskelkörperchen blieben, so viel sie auch wucherten, wie so deutlich die Fasern oberhalb der Ligatur zeigten (s. Versuch 6-8), immer Kerne und zeigten niemals auch nur den geringsten Protoplasmahof. Ein wie grosser Unterschied zwischen den Kernen in den Zellen waltet, die in den unterhalb der Quetschstelle befindlichen Muskeln vom dritten Tage an ungefähr auftreten, lehrt ein einfacher Vergleich. Die Zellen lassen alle Uebergänge vom farblosen Blutkörperchen bis zu den grossen, mit der zerfallenen contractilen Substanz versehenen Zellen constatiren, während ich einen allmählichen Uebergang von wuchernden Kernen bis zu Zellen in den alten Muskelfasern nicht nachweisen konnte, vielmehr nur ein vollständig reactionsloses, passives Verhalten derselben. Ich interpretire daher die Zeichnungen Kraske's I und II ganz anders. Sie entsprechen den Figuren 1 und 2 der meinigen, die eine Durchsetzung der Muskeln mit farblosen Blutzellen illustriren.

Kraske versichert, dass die Kerne bei $b$ und $c$ ihr Protoplasma innerbalb der Muskelfasern bekommen haben. Allein so gewiss ist das doch nicht; es können ebenso auch Zellen in die Fasern eingedrungen sein und dort weitere Veränderungen eingehen. S. 12 spricht Kraske von Wanderzellschlauchen, S. 15 weist er aber Gussenbauer's Interpretation seiner Zeichnung in diesem Sinne zurück, und später fehlt auch jede Erörterung über die Schicksale der vou ihm oft gesebenen Wanderzellschläuche.

Da Kraske, wie er selbst sagt, eine Eiterung der Muskelwunde bei seinen Versuchen möglichst $z u$ vermeiden suchte, sie bei den meinigen aber in dẹ Vordergrund trat, so vermag ich über die Richtigkeit seiner Beobachtungen, betreffend die weiteren Regenerationsvorgänge kein Urtheil zu fällen.

Die weiteren Schicksale der Wanderzellschläuche stellen sich folgendermaassen dar: Nachdem die Wanderzellen in die Muskel-

1) l. c. S. 12 . 
fasern eingedrungen sind, zerstören sie zunächst den contractilen Inhalt, der an sich schon durch die Circulationsunterbrechung einer Degeneration anheimgefallen ist, und nehmen ihn als grobkörnige Masse in sich auf, oder er lagert sich dem Protoplasma der Zellen an und verschmilzt mit ihm (Fig. 3, 4, 5 bei b).

Dieser Vorgang dürfte nicht so viel Auffälliges haben, als es Anfangs scheinen könnte. Wenn die Wanderzellen, wie allgemein angenommen wird, Fetttröpfchen und Pigmentkörnchen in sich aufzunehmen vermögen, warum sollten sie sich denn nicht auch mit der weichen, plastischen, contractilen Substanz vereinigen können? Eine ähnliche Function der contractilen Substanz nimmt übrigens auch Gussenbàuer an, und lässt er sie um die gewucherten Kerne sich lagern und diese so zu Muskelzellen werden. Desgleichen auch Kraske.

Durch die Aufnahme des veränderten Muskelinhalts werden die Zellen ausserordentlich gross, fast wie Epithelien. Ihre runde Form wechseln sie sehr bald und nehmen eine längsovale, spindelartige, zackige an, während sie sich immer in der Längsrichtung der früheren Muskelfasern lagern, ein Vorgang, der durchaus nur auf mechanischem Wege zı erklären sein dürfte, da das zurückbleibende und wuchernde Perimysium und die erhaltenen Theile des Sarkolems ihnen eine andere Richtung einzunehmen nicht gestatten (Fig. 2 d). Dann folgt die Verschmelzung der so gebildeten Spindelzellen, eine hinter der andera, zu schmalen Bänderchen, in denen Anfangs so viele Kerne vorhanden zu sein scheinen, als Zellen sie gebildet haben. Ich bekam. solche Bänder zur Anschauung, die noch deutlich ihre Zusammensetzung aus Spindelzellen erkennen liessen. Später wuehern die Kerne, und wir erhalten dann ähnliche Gebilde, wie sie Gussenbauer darstellt, nur hängen sie nicht mit den alten Fasern zusammen.

Dieser Vorgang entspricht ganz den Anschauungen, die Kölliker und Schwann über die Bildung junger Muskelfasern schon lange ausgesprochen haben. Aus meinen Versuchen geht hervor, dass die ersten Anfänge der Bildung junger Fasern schon nach $3 \frac{1}{2}$ Tagen (s. Versuch 6) beginnen, und dass man noch in späteren Stadien, wie Versuch 8 beweist, neben schon weiter ausgebildeten Fasern auch die ersten Keime sich finden. Verschiedene Entwicklungsstadien der Muskeln sind also neben einander vorhanden. 
Neben diesem Prozess scheint mir jedoch noch ein anderer Modus der Neubildung, nebmlich ein Spaltungsprozess der alten Muskelfasern vorzukommen. Wenn man sich vergegenwärtigt, dass die Muskelfasern Gebilde von ziemlicher Längenausdehnung sind, so wird man es auch nicht auffallend finden, dass sich in ihnen verschiedene Grade der Degeneration bemerkbar machen. Während ein Theil der Fasern den oben besprochenen Zerfall ihrer bistologischen Structur und die Auflösung durch Wanderzellen zeigt, hat ein anderer Theil eine gewisse Widerstandskraft behalten. Er zeigt zwar keine Kerne, aber Querstreifung und auch eine besonders hervortretende Längsstreifung, die schliesslich in Spaltenbildung ubergeht (Fig. 6 a und b). In ersterer sieht man unten ein schmales, abgespaltetes Stück obne Kerne mit leichter Längsund Querstreifung. Dieser Spaltungsprozess, der theils durch die degenerativen Vorgänge in der Muskelfaser selbst, theils durch die Wanderzellen bedingt wird, welche in die Spalten eindringen und sie vergrössern, wird nun die Ursache der Bildung neuer Fasern, je nachdem die alte Faser in mehrere sehr schmale oder in wenige etwas breitere zerfällt. Ob diese abgespalteten Fasern auch von den Wanderzellen ber ihre Kerne erhalten, oder auf andere Weise, darüber babe ich keine directen Beobachtungen machen können; wenn aber die Bildung junger Fasern aus den Wanderzellschläuchen richtig ist, so dürfte auch dieser Vorgang an Wahrscbeinlichkeit gewinnen. Bemerkenswerth ist ferner, dass in diesem frühen Stadium der Heilung die Kerne noch wenig Aehnlichkeit mit denen normaler Muskeln haben. Man findel sie oft in einer Reibe hintereinander gelagert, wobei die anstossenden Flächen abgeplattet sind; oft auch zu Gruppen von $3-6$ zusammen, diese erscheinen dann von einem gemeinsamen Protoplasmahof umschlossen zu sein. Allmählich aber werden sie den wuchernden Kernen entzündeter Muskeln ähnlich, und man hat dann ein Bild, wie es in Versuch 8 die Plantamuskeln zeigen, deren Kerne durcbaus ähnlich sind den wuchernden Kernen oberhalb der Ligaturstelle.

Dies sind die Heilungsvorgänge an den entfernt von der Quetschstelle gelegenen Muskeln, wie sie sich bis zum neunten Tage nach meinen Beobachtungen darstellen. Da es mir für die späteren Stadien dieses Prozesses an genügendem Material fehlt, so behalte ich mir die Darstellung der definitiven Resultate der Heilung einer spätern Zeit vor. 
Es erübrigt noch, auf die Veränderungen kurz einzugehen, welche sich an den von dem Gummischlauch gequetschten Muskeln und in deren unmittelbarer Năhe nach oben und unten hin documentirten.

Was die erste der genannten Stellen betrifft, so leachtet ein, dass die Muskelbündel, da sie hier den grössten Insulten ausgesetzt gewesen sind, auch am schnellsten der Nekrose anheimfallen werden. Und dieses bestätigt sich, soweit meine Untersuchungen reichen, vollkommen. Makroskopisch sahen wir hier eine exquisit weisse Farbe besonders in Versuch 8 in Folge der totalen Anämie der Gefässe. Vollständiger Kernschwund tritt sehr bald ein, die Querstreifung erbält sich aber mit grosser Dentlichkeit bis zuletzt, während die Fasern ihre Elasticität verlieren, wie die vielfachen Einrisse mit Evidenz beweisen. Auch die chemische Natur des contractilen Inhalts scheint sich zu modificiren, denn mit Hämatoxylin behandelte Muskeln färbten sich nicht blau, sondern erhalten ein fahles, schmutziggelbes Aussehen. Zwischen den Fasern sieht man rothe Blutkörperchen in mehr oder minder grosser Menge, weniger farblose, niemals eine zellige Infiltration, wie man erwarten könnte. Welches das schliessliche Schicksal dieser Stelle ist, vermag ich nicht zu entscheiden. In dem Fall 9 war ein Detritusknoten daraus geworden. $\mathrm{Ob}$ dies immer so ist, oder ob das Muskelgewebe von oben da hineinwächst oder ob der Substavzverlust durch ein Narbengewebe ausgefüllt wird, werden spätere Untersuchungen lebren.

Was die dicht über und unterhalb der Ligatur befindlichen Muskeln betrifft, so sehen wir zunächst oberhalb, also dem gesunden Gewebe angrenzend, eine Zone zerrissener und zerklüfteter Muskelfasern sich bilden, eine Erscheinung, dje natürlich direct auf den mechanischen Insult der Umschnürung zurückzuführen ist. Daher jst es denn auch nicht auffallend, dass zunächst eine sehr zellenreiche Infiltration zu Stande kommt, denn die Muskelfasern sind zerstört, die Capillaren eingerissen und so dem Eindringen von Blut und Wanderzellen uberhaupt kein Hinderniss entgegengesetzt. Auch hier beobachtete ich daher ein Zerfallen der Schollen und Aufnahme derselben von den Wanderzellen, die, je länger das Thier lebt, auch weiter nach unten vordringen. Schliesslich kommt in derselben Weise eine Regeneration zu Stande, wie an der weit unterhalb der 
Ligatur gelegenen Musculatur. Die Infiltration des Perimysiums erstreckt sich aber noch weiter nach oben hinauf und drängt die Fasern auseinander, obne ihnen zu schaden. Dagegen reagiren sie auf den Reiz der Quetschung durch eine starke Kernwucherung, jedoch keineswegs so schnell und iutensiv, als man erwarten dürfte. Denn wie ich bei der Beschreibung der Versuche schon erwähnte, fand ich erst vom 6. Versuch an eine reichliche Kernvermehrung. Hier muss ich ganz besonders auf den Unterschied aufmerksam machen, der in dieser Kernwucherung der lebenskräftigen und in einen entzündlichen Zustand versetzten Muskeln sich ausprägt, gegenüber jener der neu entstandenen Fasern, deren Kerne ich als aus den Wanderzellen hervorgegangen betrachte. Diese sind klein und rund und befinden sich an allen Stellen des dicken Durchmessers der Fasern, sind also auf Querschnitten auch in der Mitte zu sehen, während jene sich als belle mit Kernkörperchen versehene Bläschen rund oder oval darstellen, die eine peripherische Anordnung besitzen, wie ja auch die normalen Muskelkerne sich stets nur am Rande, nie innerbalb einer Faser finden.

Wie die jungen Muskelfasern an der Ligaturstelle mit den alten über derselben in Verbindung treten, darüber geben meine Präparate noch keinen Aufschluss. Bis zum 9. Tage zeigt sich dort noch eine ziemlich scharfe Grenze. Eine solche Verbiudung ist in dieser Zeit überhaupt noch nicht vorhanden.

Schliesslich sei mir noch gestattet, die Resultate meiner Untersuchungen in folgenden Sätzen kurz zu formuliren.

Eine Circulationsunterbrechung von 8-10 Stunden einer ganzen Extremität hat eine erbebliche Ernährungsstörung aller unterbalb der Ligatur befindlichen Gewebe zur Folge. Auf die Musculatur äussert sich dieselbe

a) darin, dass die Muskelfasern ihre Kerne verlieren, die contractile Substanz trübe, körnig wird und ihre Elasticität einb tisst.

b) Dass neben einer sehr reichlichen Infiltration des Bindegewebes mit Wanderzellen, dieselben in uberaus grosser Zahl in die degenerirten Muskelfasern eindringen und sie zu einer vollständigen Auflösung oder Abspaltung schmaler Fasern zwingen.

c) Dass in der jetzt eintretenden Regeneration das nekrotische 
Muskelgewebe durch den Heilungsprozess nicht als unbrauchbar ausgestossen wird, sondern als Näbrmaterial für die jungen Muskelfasern verwendet, die aus den modificirten Wanderzellen hervorgehen.

Das neben diesem Regenerationsprozess nicht auch ein anderer, wie ihn Weber, Waldeyer, Neumann, Gussenbauer und Andere beobachtet haben, vorkommt, wage ich nicht zu bestreiten. Wie schon im Anfang dieser Arbeit hervorgehoben wurde, dürte die besondere Art des Traumas, die von der von den frühern Autoren benutzten doch wesentlich abweicht, neben den eigenthümlichen pathologischen Veränderungen der Muskeln auch eine dem entsprechend modificirte Neubildung derselben bedingen.

Es ist mir eine angenehme Pflicht, am Schlusse dieser Arbejt meinem hochverehrten Lehrer, Herrn Professor Neumann, für seine vielfache Unterstïtzung, die er mir zu Theil werden liess, meinen verbindlichsten Dank abzustatten.

Um einer irrthümlichen Meinung vorzubengen, bemerke ich noch, dass Herr Professor Neumann mit meiner Auffassung von der Regeneration der Muskelfasern nicht übereinstimmte.

\section{Erklärung der Abbildungen. \\ Tafel II.}

Fig. 1. Querschnitt einer Stelle der vordern Unterschenkelmusculatur von Versuch 8 (Hartnack System 4, Ocular 4). Die breiten, polygonalen Felder stellen Querschnitte alter Muskelfasern grösstentheils ohne Kerne dar. Bei a vollständiges Durchdringen der Muskeln mit Zellen, bei $b$ beginnende Einwanderung, bei $\mathbf{c}$ vollständiges zelliges Iofiltrat mit Zerstörung der Muskelfelder, d Nerven -, e Gefässquerschnitt.

Fig. 2. Längsschnitt der Wadenmusculatur von Versuch 8 (H. System 4, Oc. 4). a Im Untergang begriffene alte Fasern, die theilweise eine Querstreifung noch erkennen lassen. b Durch Zelleneinwanderung unterbrochene Fasern. c Muskelscholle mit Querstreifung. d Kleinzelliges Infiltrat ohne Spuren alter Muskelfasern mit Anordoung der Zellen in der Längsrichtung der untergegangenen Muskeln (Wanderzellenschläuche).

Fig. 3. Die Stelle a, von Fig. 2 bei starker Vergrösserung (H. S. 7, Oc. 4). Bei a Muskelscholle mit Querstreifung, bei b grosse Zelle mit körnigem Inhalt.

Fig. 4 n. 5. Längsschnitte von anderen Stellen, bei a Muskelscholle, b grosse Zelle mit grobkörnigem Protoplasma. Wanderzellschlanch.

Fig. 6. Zwei Muskeln in Längstibrillen zerfalleod ron Versuch 7.

Fig. 7. Querschnitt von der Wadenmusculatur von Versuch 9. Wucherang des Perimysiums. Bei a Theilung eines Muskelfeldes in zwei kleinere.

Alle Abbildungen sind mit Hülfe des Hartnack'schen Zeichenapparats ausgeführt. 